Revistade
Economild
Contemporâned

\title{
OUTRO OLHAR PARA O FINANCIAMENTO DA PREVIDÊNCIA SOCIAL NO BRASIL: A CENTRALIDADE DA FORMALIZAÇÃO DO TRABALHO, AUMENTO DE PRODUTIVIDADE E GESTÃO DE RECEITAS
}

\author{
Denise Lobato Gentil ${ }^{a}$ \\ Eliane Cristina de Araújo ${ }^{b}$ \\ Claudio Alberto Castelo Branco Puty ${ }^{c}$ \\ Carlos Patrick A. Silva ${ }^{d}$

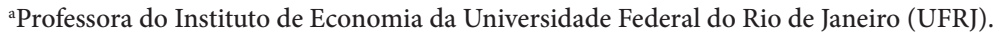 \\ Rio de Janeiro, RJ, Brasil. ORCID: http://orcid.org/0000-0002-9979-700X. \\ 'Professora da Universidade Estadual de Maringá (UEM). Maringá, PR, Brasil. \\ ORCID: https://orcid.org/0000-0001-5104-2508. \\ 'Professor da Universidade Federal do Pará (UFPA). Belém, PA, Brasil. \\ ORCID: https://orcid.org/0000-0002-9618-9770. \\ ${ }^{\mathrm{d} P e s q u i s a d o r}$ do Laboratório de Tecnologias Sociais do Programa de Pós-Graduação em Engenharia \\ Elétrica da Universidade Federal do Pará (UFPA). Belém, PA, Brasil. \\ ORCID: http://orcid.org/0000-0002-6979-8052.
}

Recebido em 20 janeiro 2018

Aceito em 19 dezembro 2019

RESUMO: $\mathrm{O}$ artigo discute as variáveis relevantes para o financiamento da previdência social no Brasil, que têm sido desconsideradas no debate. Inicialmente, apresenta-se um modelo teórico que indica a relevância da produtividade, da formalização do trabalho e da eficiência de receitas para o financiamento da previdência. Analisa-se, na sequência, a trajetória dessas variáveis no Brasil, com sugestões de medidas para estimulá-las. Por

Correspondência para: Denise Lobato Gentil

Contato: denisegentil@ie.ufrj.br 
fim, um exercício de simulação é realizado para testar os efeitos de mudanças nas variáveis sugeridas pelo modelo teórico sobre os resultados da previdência. As conclusões indicam que, quando considerados choques positivos na produtividade do trabalho, emprego formal e receita da previdência, o Regime Geral da Previdência Social (RGPS) torna-se superavitário. Uma implicação desse resultado é que os problemas de financiamento da previdência social não são resolvidos pelo corte de benefícios.

PALAVRAS-CHAVE: reforma da previdência social; eficiência da receita; produtividade do trabalho; formalização da força de trabalho; economia brasileira.

CLASSIFICAÇÃO JEL: H55; H58; J11; J21; J24. 


\title{
ANOTHER LOOK AT THE FINANCING OF SOCIAL SECURITY IN BRAZIL: THE KEY ROLE OF FORMALIZING WORK, INCREASING PRODUCTIVITY AND ENHANCING REVENUE MANAGEMENT
}

\begin{abstract}
This article analyzes a set of variables deemed relevant for the financing of social security in Brazil, which have been overlooked in the recent debate on the subject. At first, we introduce a theoretical model that highlights the key role of increasing productivity, expanding formal employment, and enhancing revenue efficiency in the financing of social security. We then analyze the trajectory of these variables in Brazil and suggest measures to stimulate them. Finally, we perform a simulation exercise to test the effects of changes in the selected variables on the outcomes of social security. The results indicate that in face of positive shocks in labor productivity, formal employment, and pension income, the General Social Security System (RGPS) results become a surplus. A key implication of this result is that problems in the financing of social security cannot be solved exclusively by cutting benefits.
\end{abstract}

KEYWORDS: pension reform; revenue efficiency; labor productivity; formal employment; Brazilian economy. 


\section{INTRODUÇÃO}

A discussão convencional vigente na economia brasileira sobre previdência social ressalta a crise causada pelo envelhecimento da população e suas consequências negativas para o financiamento do sistema. Isso porque o regime previdenciário público adotado no Brasil, como na maioria dos países, é o de repartição simples, que funciona com a cobrança de contribuições sociais das pessoas que estão em atividade para o financiamento das aposentadorias e pensões daquelas que já estão aposentadas. Com o envelhecimento da população, haveria menos pessoas trabalhando para financiar um número cada vez mais elevado de aposentados, o que culminaria em deficit crescentes, cuja solução passaria por uma reforma que envolve redução dos benefícios, aumento da idade mínima para se aposentar, elevação do tempo de contribuição e estímulo a sistemas privados complementares de aposentadoria. ${ }^{1}$

Diferentemente dessa análise que busca solucionar os problemas da previdência social com o corte de benefícios, este estudo se propõe a discutir outras variáveis importantes para o financiamento do sistema, frequentemente omitidas do debate sobre os sistemas de proteção social, e sugerir medidas alternativas que possam contribuir para a solução desse impasse. Embora este o artigo tenha sido escrito no ano de 2017, fortemente influenciado pela conjuntura de debates em torno da reforma da previdência encaminhada pelo então presidente Michel Temer (2016), uma característica da presente pesquisa é que a parte teórica não está circunscrita a um período histórico específico e nem limitada à interpretação do Brasil, podendo suas conclusões serem válidas para o debate da previdência de maneira abrangente. Quanto à parte empírica, foi empregada a modelagem econométrica para as projeções de receita e despesa da previdência social disponibilizadas pelo governo federal através da Lei de Diretrizes Orçamentária (LDO) de 2013. Vale ressaltar que o modelo econométrico atuarial usado pelo atual Ministério da Economia do governo do presidente Jair Bolsonaro (2019) para a apresentação da proposta de reforma da previdência (PEC n 6/2019, que depois se transformou em Emenda Constitucional no 103 de 12/11/2019) possui lógica semelhante ao disponibilizado em 2013, salvo alguns reparos específicos que não alteram as conclusões finais desta pesquisa. ${ }^{2}$

O trabalho divide-se em três partes, além desta introdução. A primeira apresenta um modelo teórico para sugerir variáveis relevantes e alternativas para o entendimento do financiamento da previdência social, tendo como referência principal o artigo de

\footnotetext{
1 Sobre as características dos arranjos previdenciários, ver Barr (2004) e Barr e Diamond (2008).

2 Para uma avaliação comparativa, ver Da Silva (2017) e Gentil (2019a).
} 
Eatwell (2002). A segunda parte analisa o comportamento dessas variáveis no Brasil e sugere medidas para estimulá-las, de forma que repercutam em ampliação das receitas do sistema previdenciário. A terceira seção simula, através do modelo econométrico utilizado pelo Ministério da Previdência Social do governo do então presidente Michel Temer (ampliado, neste estudo, pelos autores), os efeitos de mudanças nas variáveis sugeridas na seção teórica sobre os resultados da previdência social. Três cenários são testados: um pessimista, outro moderado e um terceiro, otimista.

As principais conclusões deste artigo indicam que, quando considerados choques positivos em variáveis como produtividade do trabalho, emprego formal e receita da previdência, os resultados financeiros do Regime Geral da Previdência Social (RGPS) tornam-se positivos. Uma implicação importante desse resultado é que os problemas de financiamento da previdência social no Brasil não precisam, e não devem, ser resolvidos unilateralmente pelo corte de benefícios, mas podem conectar-se a medidas que estimulem o crescimento econômico, a formalização do trabalho, o crescimento da produtividade do trabalho e o aumento das receitas da previdência social.

\section{ENTENDENDO OS DETERMINANTES FUNDAMENTAIS DO FINANCIAMENTO DA PREVIDÊNCIA SOCIAL}

A discussão tradicional sobre o financiamento da previdência social enfatiza sempre a redução do número de benefícios como a única medida capaz de resolver os problemas de deficit da previdência. No entanto, tendo como referência o artigo de Eatweel (2002) é possível apresentar uma visão diferenciada dessa questão, baseando-se em um modelo simplificado que permite entender as variáveis fundamentais para a análise do financiamento de um sistema de previdência social. ${ }^{3}$

A análise parte da seguinte relação:

$$
A P N=(S+T) \varepsilon_{L} L
$$

Nessa equação $A P$ é a aposentadoria média per capita por ano; $N$ é o número de aposentados; $S$ é a propensão média a poupar; $T$ é a alíquota de impostos; e $L$ e $\varepsilon_{L}$ são, respectivamente, o número de trabalhadores formais (contribuintes) e o valor do produto per capita, ou a produtividade da população ocupada. Sendo assim, $\varepsilon_{L} L$ é o

\footnotetext{
O modelo apresentado por Eatwell (2002) considera que os aposentados são o único grupo dependente da população e que a poupança e os impostos são direcionados para a provisão de bens e serviços para os aposentados, ignorando outros usos para essas variáveis.
} 
fluxo de produção de bens e serviços. Já a poupança e os impostos são a forma de extrair da população ocupada os bens e serviços que a população aposentada necessita.

Embora a equação (1), em uma primeira aproximação, pareça extremamente simples, entende-se que outras variáveis igualmente importantes para explicar os resultados da previdência social estão, de forma implícita, consideradas nessa equação. Dessa forma, as variáveis de mercado (grau de formalização, taxa de desemprego, taxa participação, etc.), variáveis demográficas (expectativa de sobrevida após a aposentadoria) e demais variáveis (anos de trabalho, idade média de entrada na força de trabalho, etc.) estão contempladas indiretamente pelas variáveis da equação (1).

O lado esquerdo da equação representa o valor do total das aposentadorias pagas anualmente e o lado direito ilustra o total de bens e serviços da economia que não são apropriados pela população ocupada, isto é, que são poupados ou pagos como impostos e são utilizados para o pagamento dos aposentados.

As variáveis poupança e impostos representam, respectivamente, a proporção do valor produzido que é convertido para a previdência na forma de contribuição do trabalhador sobre seu salário, somada à alíquota de contribuições previdenciárias pagas pelo empregador sobre a folha de salários.

Se considerarmos, assim como em Eatwell (2002), essa transferência como sendo igual a $R$, isto é, $R=S+T$, sendo $S=S a$ e $T=T(1-a)$, a equação anterior pode ser rearranjada como segue:

$$
A P N=R \varepsilon_{L} L
$$

$\mathrm{Ou}$

$$
\frac{N}{L}=\frac{R \varepsilon L}{A P}
$$

Reescrevendo a equação (3) em termos de taxas de crescimento, temos:

$$
\dot{N}-\dot{L}=\dot{R}+\varepsilon \dot{L}-A \dot{P}
$$

Essa equação mostra, portanto, a taxa de crescimento da população aposentada $\dot{N}$, a taxa de crescimento da força de trabalho $\dot{L}$, a taxa de crescimento da produtividade do trabalho $(\varepsilon \dot{L})$, a taxa de crescimento do valor real das aposentadorias $A \dot{P}$ e a taxa de crescimento dos impostos e da poupança $\dot{R}$.

Com base na equação (4), a crise da previdência social ocorre porque o envelhecimento da população implica uma taxa de crescimento de aposentados maior do que a taxa de crescimento da força de trabalho contribuinte. Quando isso acontece, o lado direito da equação (4) também precisa ser positivo, isto é, as taxas de crescimento 
da produtividade e dos impostos e poupança devem ser superiores à taxa de crescimento do valor real das aposentadorias. ${ }^{4}$

Essa relação evidencia o fato de que o envelhecimento da população pode ser contornado por três diferentes políticas, além da redução no valor real das aposentadorias, quais sejam:

i) incrementos na produtividade;

ii) aumento da poupança e dos impostos;

iii) aumento na taxa de crescimento do emprego formal, isto é, do número de contribuintes.

O senso comum costuma sugerir como solução para a crise da previdência social apenas a redução no valor das aposentadorias e do número de benefícios, aumento da idade mínima para se aposentar, elevação do tempo de contribuição e estímulos aos sistemas privados de aposentadoria. No entanto, a análise do financiamento do sistema de previdência social deve ser entendida tendo-se em mente o comportamento das três variáveis acima enumeradas, que produzem efeitos do lado da receita do sistema, e não apenas enfatizar a redução do gasto com aposentadorias.

Considerando esse panorama, nas próximas seções serão investigados os efeitos dessas políticas alternativas sobre os resultados da Previdência.

\section{DINÂMICAS RECENTES DA PRODUTIVIDADE, EMPREGO E RECEITAS DA PREVIDÊNCIA NO BRASIL}

\subsection{PRODUTIVIDADE, RAZÃO DE DEPENDÊNCIA E CRISE DA PREVIDÊNCIA SOCIAL}

Para entender os efeitos de um incremento na taxa de crescimento da produtividade, uma variável chave é a chamada razão de dependência $(d)$, que é a relação entre o número de aposentados $(N)$ e o número de trabalhadores $(L){ }^{5}$

4 Note-se que em uma situação na qual haja acúmulos de superavit, mesmo com o lado direito menor que o esquerdo, dependendo dos valores, o tempo para a ocorrência de uma crise pode ser elevado.

5 Existem outras definições de taxas de dependência. A Organização das Nações Unidas, por exemplo, divulga uma taxa de dependência total ((Idade 0-14 + Idade 65+) / Idade 15-64)), infantil (idade 0-14 / idade 15-64) e de idosos (idade 65+ / idade 15-64) (UN, 2019). Algumas estimativas de taxa dependência também incluem a taxa de participação da força de trabalho para cada faixa etária. O Bureau of Labor Statistics, do Departamento de Trabalho dos Estados Unidos, realiza essa estimativa para cada incremento de cinco anos da população a partir dos 16 anos. O cálculo revela, por exemplo, que a força de trabalho está caindo globalmente porque as pessoas de 16 a 24 anos estão na escola ao invés de ingressar na força de trabalho, de forma que os outros grupos etários estão assumindo esse espaço (BLS, 2020). 


$$
d=\frac{N}{L}
$$

Por ela é possível observar que o aumento da longevidade da população implica no aumento de aposentados $(N)$ que amplia a razão de dependência dos aposentados em relação aos trabalhadores ativos. No entanto, conforme destaca Palley (1998), se considerarmos que os trabalhadores se tornam cada vez mais produtivos, esse fato tende a reduzir a carga real de apoio aos aposentados. Dito de outra forma, um aumento da produtividade pode ser traduzido como se fosse um aumento no número efetivo de trabalhadores. ${ }^{6}$

Segundo Palley (1998), esse número de trabalhadores efetivos pode ser determinado pela fórmula que ilustra que o número de trabalhadores efetivos no período $t$ é igual ao número de trabalhadores do período $t$ - 1 acrescido de sua taxa de crescimento e da produtividade do trabalho.

$$
L_{t}^{\prime}=\left(1+\dot{\varepsilon}_{L}+\dot{L}\right) L_{t-1}
$$

Sendo assim, o crescimento da produtividade, conforme explica Palley (1998), pode ser usado para calcular o número de trabalhadores efetivos $\left(L^{\prime}\right)$, isto é, o número de trabalhadores aumentados pelo efeito cumulativo do crescimento da produtividade. Isso dá origem à noção de razão de dependência econômica efetiva $\left(d^{\prime}\right)$, que é definida como:

$$
d^{\prime}=\frac{N}{L^{\prime}}
$$

O aumento da produtividade, que é equivalente ao aumento do número de trabalhadores efetivos, significa que a quantidade de produto que se obtém utilizando uma unidade de trabalho é maior. Portanto, se considerarmos a possibilidade de incrementos na produtividade, a iminente ameaça de uma crise causada pelo envelhecimento da população e suas consequências para o financiamento da previdência social mudam sobremaneira, pois incrementos contínuos na produtividade do trabalho implicam reduções contínuas da razão de dependência econômica efetiva

6 Nessa mesma perspectiva, Rada (2009) argumenta que uma forma de lidar com a crescente taxa de dependência é assegurar a sustentabilidade do crescimento econômico, que, simplificadamente, depende da taxa de crescimento do trabalho e da taxa de crescimento da produtividade do trabalho. Com o maior crescimento econômico, há a ampliação dos recursos reais disponíveis para financiar os benefícios da previdência social. 
da economia, afastando os impactos negativos do envelhecimento populacional para o financiamento da previdência social.

Sobre a importância da produtividade para os sistemas de aposentadorias públicos, Palley (1998) destaca ainda que a questão da distribuição de renda é central para o problema do envelhecimento populacional, enfatizando a importância da elevação da produtividade e da renda total da economia. No caso da produtividade, coloca o autor, essa é uma variável estratégica para se pensar os sistemas de previdência social, uma vez que o aumento da produtividade dos trabalhadores decorrente do progresso tecnológico implica a redução da carga real de apoio aos aposentados, como se o número "efetivo" de trabalhadores estivesse aumentando via incrementos na produtividade do trabalho. Já no que se refere à renda total, o seu crescimento deve ser suficiente para o provimento de uma renda de substituição à população idosa, como também este crescimento deve ser repassado aos trabalhadores, pois, se o sistema é financiado mediante a cobrança de impostos sobre salários, então os salários também devem crescer para que os recursos destinados ao pagamento de aposentadorias e pensões cresçam com eles. Portanto, conclui o autor, estimular a produtividade e evitar a estagnação salarial são fundamentais para o financiamento dos sistemas de pensões públicos.

No que se refere ao comportamento da produtividade no Brasil, a Figura 1, a seguir, ilustra a trajetória dessa variável de 1950 a 2010. Verifica-se que a produtividade seguiu trajetórias bastante distintas entre 1950 e 1980 e entre 1981 e 2010 . No primeiro período, a taxa de crescimento dessa variável foi de 4,5\% e, entre 1981 e 2010, de apenas $0,5 \%$. Portanto, a produtividade do trabalho se estagnou na crise dos anos 1980 e não mais se recuperou.

No que se refere aos determinantes da produtividade, os autores do mainstream relacionam os incrementos nessa variável a fatores do lado da oferta, como o aumento da tecnologia e o capital humano (ROMER,1986; LUCAS,1988).

Os autores heterodoxos enfatizam a importância das condições de demanda como aspecto central para explicar a evolução e a sustentação da produtividade ao longo do tempo. Ademais, não só a produtividade é relatada como um dos fatores explicativos para o crescimento sustentado, como o oposto também é verdadeiro; isto é, o crescimento da economia também explica o crescimento da produtividade, como estabelece a lei Kaldor-Verdoon (KALDOR, 1966, 1968).

Independentemente da linha teórica, ao se analisar a baixa taxa de crescimento da produtividade desde a década de 1980, observa-se que os elementos requeridos para a recuperação desse indicador estiveram ausentes no período, de forma que diversos obstáculos se apresentaram à sua evolução nas últimas décadas. O destaque foi para a longa fase de crescimento pífio, o baixo investimento em formação bruta de capital fixo e em inovação (tecnológica, formação de recursos humanos qualificados, etc.), além do uso de políticas macroeconômicas recessivas de combate à elevada inflação. 
Figura 1 - Evolução da taxa de crescimento da produtividade, Brasil, 1950-2010 (em \%)

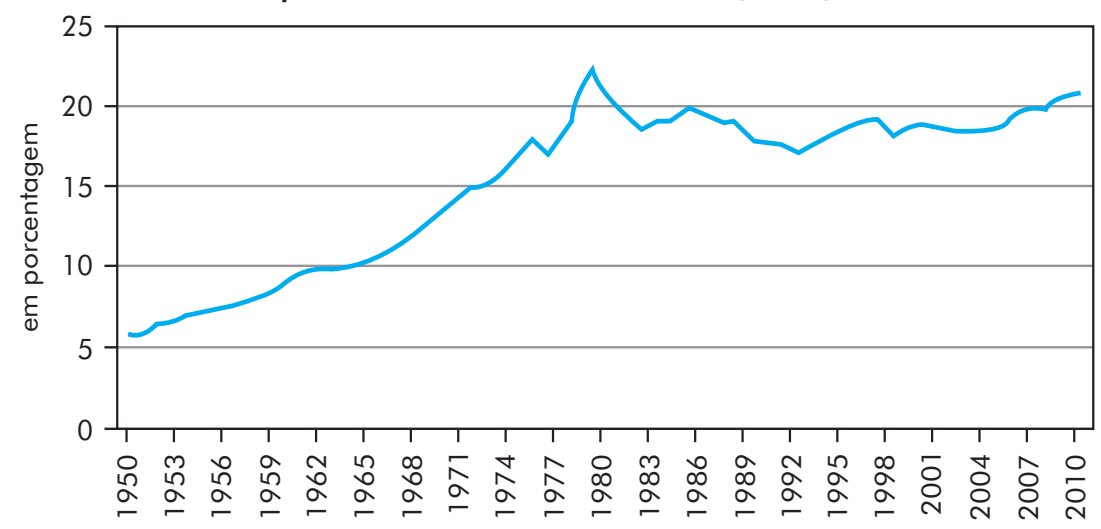

Nota: Somatória do valor adicionado dos 10 setores do Groningen Growth and Development Centre (GGDC), a preços constantes de 2005 e em milhões de reais, dividido pelo total de pessoas empregadas nesses setores. Os 10 setores são: agricultura, mineração, manufatura, construção, utilidades públicas, comércio no varejo e atacado, transportes e comunicações, serviços financeiros e empresariais, outros serviços de mercado e serviços governamentais.

Fonte: Elaboração própria com base nos dados de GGDC (2013).

Nesse sentido, um conjunto de medidas, como a combinação de mecanismos de política industrial horizontal (gastos em infraestrutura, educação, treinamento, estímulos a pesquisa e desenvolvimento) e vertical (estímulos a atividades econômicas, processos, segmentos, cadeias e setores produtivos com elevada capacidade de gerar e difundir ganhos de produtividade para o restante da economia), poderia contribuir para estimular o aumento da produtividade e o crescimento da economia como um todo.

Sendo assim, a sustentabilidade dos sistemas previdenciários públicos em regime de repartição está interligada à eficiência tanto da política industrial quanto da política macroeconômica expansionista, condições necessárias para alcançar ganhos crescentes de produtividade no longo prazo.

Por fim, vale ressaltar que, para diversas correntes de pensamento econômico, a produtividade é a chave para o crescimento sustentável da economia no longo prazo. Na prática, as evidências empíricas também mostram que o crescimento do produto interno bruto (PIB) é fortemente relacionado a incrementos de produtividade, sendo este fundamental para geração de empregos e aumento do padrão de vida das pessoas ao reduzir preços e elevar a qualidade dos produtos consumidos. A esse respeito Krugman destaca que "[a] produtividade não é tudo, mas no longo prazo é quase tudo. A capacidade de um país de melhorar seu padrão de vida ao longo do tempo depende quase inteiramente de sua capacidade de aumentar sua produção por trabalhador" (1994, p. 9). 


\subsection{CRESCIMENTO ECONÔMICO, EMPREGO E FORMALIZAÇÃO}

Após o período de estagnação dos anos 1990, a economia brasileira ingressou em uma fase de notáveis mudanças econômicas e sociais. Dentre os determinantes da retomada do crescimento (2004-2008) destacam-se dois conjuntos de fatores - internos e externos. No plano externo, ocorreu um choque positivo de oferta dado pelo boom nos preços das commodities que melhorou os termos de intercâmbio, além da elevada liquidez internacional, que tornou o país um dos maiores receptores de capital, na forma de investimento estrangeiro direto (IED) e capitais de curto prazo. No plano interno, no primeiro governo Lula (2003-2006), foi adotada uma política de estímulo à demanda agregada, com o incentivo ao consumo das famílias, facilitado, sobretudo: a) pelos ganhos reais do salário mínimo; b) pela forte expansão e democratização do crédito - que saltou de 22\% do PIB em 2002, para 40,7\% do PIB em 2008 e 45,4\% do PIB em 2010 (BCB, vários anos); e c) pelo aumento expressivo dos gastos com programas de transferência de renda.

As taxas de crescimento do PIB saltaram de 2,0\% a.a., em média, entre 1999 e 2003, para 4,81\% a.a. entre 2004 e 2008. ${ }^{7}$ Todavia, o advento da crise financeira de 2008 levou à completa reversão do cenário externo favorável, implicando no menor dinamismo das exportações domésticas. No plano interno, embora o governo tenha sustentado a política de estímulo ao consumo até pelo menos o ano de 2010, a aceleração da inflação determinou uma nova rodada de elevação da taxa básica de juros, que passa de 7,5\% a.a. em 2012 a 14,25\% a.a. em 2015, refletindo no aumento da dívida interna e na piora das contas públicas (Tabela 1).

Como é possível observar na Tabela 1, a partir de 2004, a política econômica de incentivo ao mercado interno, aliada ao cenário externo benéfico, contribuiu para a melhoria de vários indicadores (taxa de juros, inflação, dívida pública interna), repercutindo positivamente sobre o produto e, consequentemente, o mercado trabalho. ${ }^{8}$ Todavia, o agravamento da conjuntura interna, aliado aos problemas estruturais da

7 Além disso, o PIB per capita (em R \$ de 2013), que esteve praticamente estagnado entre 1995 até 2003, elevou-se de R \$ 9.618,80 em 2003 para e R \$16.292,50 em 2008 e para R \$ 19.763,90 no ano de 2010 (IBGE, 2016). Vale notar também a ascensão das camadas mais pobres da população que passaram a integrar a Classe C (grupo com renda domiciliar mensal entre R $\$ 1.126,00$ e $\mathrm{R} \$ 4.854,00$ ). Entre 2003 e 2010 cerca de 30 milhões de pessoas entraram nesta faixa de renda dando novo ímpeto ao mercado consumidor doméstico (NERI, 2010).

8 Vale notar que o desemprego seguiu em queda firme até alcançar 4,8\% a.a em 2014, atingindo seu menor nível desde 2002. Já os rendimentos reais se elevaram desde 2004, atingindo o pico em fins de 2014, período que passa de $\mathrm{R} \$ 1.777,57$ para $\mathrm{R} \$ 2.461,44$ (crescimento real de 27,8\%) (IBGE, 2016). 
economia brasileira, ${ }^{9}$ em meio à desaceleração da economia mundial ${ }^{10}$ levou a uma inflexão do crescimento observado entre 2004-2008.

Tabela 1 - Evolução dos principais indicadores macroeconômicos Brasil, 2000-2016

\begin{tabular}{|c|c|c|c|c|c|}
\hline Ano & Inflação (IPCA) & $\underset{\text { (1) }}{\text { Taxa Selic Anual }}$ & $\begin{array}{c}\text { Dívida Pública } \\
\text { Interna }{ }^{2} \text { Líquida } \\
(\% \text { PIB })\end{array}$ & PIB (\% anual) & $\begin{array}{c}\text { Taxa de } \\
\text { Desemprego } \\
\text { Aberto }^{(3)}\end{array}$ \\
\hline 2000 & 5.97 & 15.75 & 36.50 & 4.3 & 7,85 \\
\hline 2001 & 7.67 & 19.0 & 42.40 & 1.3 & 6,83 \\
\hline 2002 & 12.53 & 25.0 & 44.70 & 3.1 & 7,88 \\
\hline 2003 & 9.30 & 16.5 & 43.30 & 1.2 & 12,3 \\
\hline 2004 & 7.60 & 17.75 & 42.63 & 5.7 & 11,5 \\
\hline 2005 & 5.69 & 18.0 & 43.13 & 3.1 & 9,8 \\
\hline 2006 & 3.14 & 13.25 & 46.30 & 4.0 & 10,0 \\
\hline 2007 & 4.46 & 11.25 & 50.15 & 6.0 & 9,3 \\
\hline 2008 & 5.90 & 13.75 & 49.76 & 5.0 & 7,9 \\
\hline 2009 & 4.31 & 8.75 & 48.95 & -0.2 & 8,1 \\
\hline 2010 & 5.91 & 10.75 & 48.06 & 7.6 & 6,7 \\
\hline 2011 & 6.50 & 11.0 & 47.16 & 3.9 & 6,0 \\
\hline 2012 & 5.84 & 7.25 & 46.18 & 1.8 & 5,5 \\
\hline 2013 & 5.91 & 10.0 & 44.55 & 2.7 & 5,4 \\
\hline 2014 & 6.41 & 11.75 & 44.67 & 0.1 & 4,8 \\
\hline 2015 & 10.67 & 14.25 & 50.60 & -3.8 & 6,8 \\
\hline 2016 & 6,28 & 13,65 & 61,2 & -3.6 & 12,0 \\
\hline
\end{tabular}

Notas: (1) taxa média diária anualizada - fim de período. (2) Dívida pública interna líquida é a diferença entre passivos e ativos financeiros, denominados em moeda doméstica, do setor público não-financeiro mais Banco Central; considera-se como setor público não financeiro as administrações diretas federal, estaduais e municipais, as administrações indiretas, o sistema público de previdência social e as empresas estatais não-financeiras federais, estaduais e municipais, exceto as empresas do grupo Petrobras e do grupo Eletrobrás. (3) Dados até 2015, Pesquisa Mensal de Emprego - PME. Dado de 2016, PNAD Contínua.

Fonte: Elaboração própria com base nos dados do Sistema de Contas Nacionais (IBGE, 2016); Pesquisa Mensal de Empregos (IBGE, 2015); séries temporais do Banco Central (BCB, vários anos).

O PIB cresceu somente 1,8\% e 2,7\%, em 2012 e 2013, respectivamente; e a inflação nesses anos voltou a se situar próxima do limite superior da meta, revertendo a trajetória

9 Problemas infraestruturais não superados na fase de crescimento permaneceram estrangulando a economia brasileira, como a baixa capacidade do setor de energia, transporte, saneamento, agricultura de abastecimento interno, assim como a incapacidade de elevar investimentos em pesquisa e desenvolvimento tecnológico.

10 A taxa de crescimento médio da economia mundial, que foi de 5,1\% em 2010, caiu para 3,8\% em 2011 e 3,3\% em 2012 (IMF, 2016). 
de queda da taxa Selic. Após 2014, o país já se encontrava em um cenário de franca estagflação, que evoluiu para uma depressão em 2015 e 2016, quando o PIB apresentou queda de $3,5 \%$ e $3,3 \%$, respectivamente, e os indicadores do mercado de trabalho se deterioraram, destaque para a taxa de desemprego que, em 2016, atingiu $12 \%$.

Nesse contexto, observa-se que um dos desafios da economia brasileira consiste em não apenas garantir o crescimento econômico, mas também assegurar sua estabilidade em patamar elevado, condição imprescindível à geração de emprego e, ao mesmo tempo, à absorção dos trabalhadores no setor formal, aumentando a base contributiva do sistema previdenciário e ampliando os instrumentos de proteção social.

A Figura 2 ilustra a evolução do grau de informalidade no Brasil, calculado com base nos microdados da Pesquisa Nacional por Amostra de Domicílios (PNAD) do IBGE. Observa-se que o grau de informalidade da economia brasileira é bastante elevado, o que impacta tanto o nível de proteção ao trabalhador, quanto a capacidade tributária do Estado no que se refere ao custeio das políticas públicas, sobretudo as sociais.

Essa informalidade se manifesta pelo crescimento da taxa de desemprego, menor participação das mulheres no mercado de trabalho, principalmente as que têm a tarefa de cuidar de crianças ou idosos, o desemprego jovem, o desemprego de longo prazo, dentre outras. ${ }^{11}$

Figura 2 - Grau de informalidade no Brasil, 1992-2014

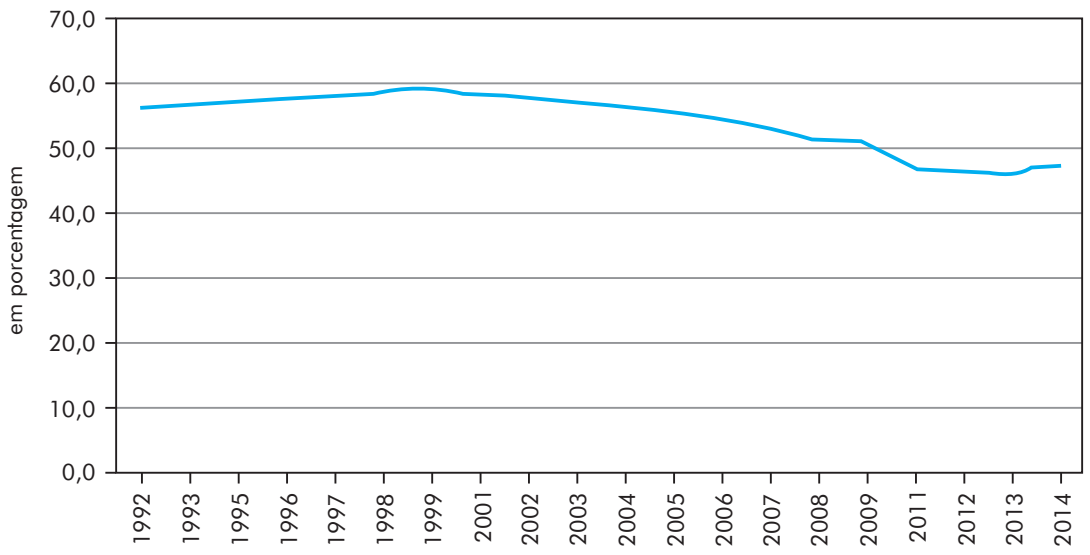

Nota: Essa taxa corresponde ao resultado da seguinte divisão: (empregados sem carteira + trabalhadores por conta própria) / (trabalhadores protegidos + empregados sem carteira + trabalhadores por conta própria).

Fonte: Elaboração própria com base nos dados de IPEA (2014).

11 Para uma análise detalhada dessa questão, ver Barr (2004). 
Sendo assim, uma variável-chave para assegurar a sustentabilidade de longo prazo do financiamento da previdência social é o aumento do emprego formal.

A esse respeito, é importante retomar o que foi abordado no item anterior deste artigo. Com o crescimento da economia impulsionado por políticas macroeconômicas expansionistas e por uma política industrial e tecnológica (geradora de progresso técnico) é esperado que ocorra o crescimento da produtividade e que surjam novas oportunidades de empregos formais, com maior poder de compra. A melhoria dos salários impulsiona o consumo e o PIB, uma vez que cerca de $60 \%$ do PIB brasileiro está alocado em consumo.

A reestruturação da cadeia produtiva industrial é decisiva para esse movimento no caso brasileiro. Parte relevante da demanda por bens industriais é oriunda da própria indústria, na forma de insumos. O crescimento nesse setor transborda no aumento da demanda por bens finais, a qual se multiplica por toda a economia, gerando empregos formais e renda em diversos setores. ${ }^{12}$

Para isso destacam-se algumas políticas pelo lado da oferta e outras pelo lado da demanda que poderiam contribuir para o aumento da taxa de participação da mão de obra no Brasil.

Pelo lado da demanda, como observado anteriormente, a geração de emprego formal no Brasil é, em grande parte, decorrência do aumento da produtividade e do produto, pois com o crescimento econômico uma parte considerável de mão de obra do setor informal é normalmente apropriada pelo setor formal do mercado de trabalho (SIMÃO, 2019).

Sobre as políticas do lado da oferta, Barr (2004) destaca a importância de maiores investimentos na qualificação da mão de obra mediante o aumento da quantidade e qualidade da educação e programas de treinamento da mão de obra, bem como o aumento da participação na força de trabalho através das reduções das taxas de desemprego e incentivo à participação da mulher na força de trabalho, com a ampliação do número de creches, escolas públicas em tempo integral e políticas voltadas para os cuidados com as crianças.

\footnotetext{
12 Sobre modelos de crescimento que incorporam a ideia de que a condução da política macroeconômica influencia o ritmo do desenvolvimento econômico e o progresso técnico em economias em desenvolvimento ver Oreiro (2016).
} 


\subsection{AUMENTO DAS RECEITAS DA PREVIDÊNCIA SOCIAL}

Como ressaltado anteriormente, o debate sobre a previdência social tem se concentrado sempre na necessidade de redução dos gastos para resolver os problemas de financiamento. No entanto, conforme se chama atenção na discussão teórica deste artigo, o equilíbrio financeiro da previdência social passa também pela possibilidade de elevar as receitas, sem sacrificar o desenho atual dos benefícios desse sistema no Brasil, tido como limitado em seu alcance e profundidade. ${ }^{13}$

No modelo teórico discutido neste artigo, as receitas da previdência social são oriundas das alíquotas de contribuição incidentes sobre a folha de pagamentos recolhida pelos empregados e empregadores. No entanto, é importante ressaltar que a previdência social possui outras fontes de receitas, como as contribuições incidentes sobre o lucro e o faturamento, também destinadas ao financiamento da previdência social, que serão discutidas a seguir.

Considerando-se o caso brasileiro, é possível sugerir algumas formas de melhorar a gestão dos recursos da seguridade social e elevar suas receitas, a saber:

i) revisão das desonerações tributárias;

ii) redução das desvinculações dos recursos da seguridade social;

iii) recuperação de forma mais eficiente dos créditos da previdência; $\mathrm{e}$

iv) realocação do saldo da conta única do Tesouro Nacional no Banco Central.

\section{Revisão das desonerações tributárias}

Durante os anos 2000, o governo federal colocou em prática uma ampla política de desonerações de tributos que tinha como objetivo estimular o investimento privado, gerar emprego e melhorar as condições de competitividade da indústria nacional. Essa política, entretanto, não resultou no crescimento do investimento e, pelo contrário, houve uma queda significativa nas taxas de crescimento dessa variável. No período 2011-2014, a taxa média anual de crescimento real do investimento foi de apenas 1,8\% contra 9,9\% no período 2007-2010. Sem conseguir cumprir com os resultados esperados, as desonerações apenas provocaram queda importante nas receitas da Previdência Social e privaram a sociedade de recursos que poderiam ter sido empregados de forma mais eficiente para gerar bem estar.

${ }^{13}$ Cabe mencionar que, apesar do avanço na cobertura conquistado nos anos 2000, o Brasil ainda possuía 23,8 milhões de trabalhadores (27,5\% da população ocupada entre 16 e 59 anos de idade) sem cobertura previdenciária em 2015 (BRASIL, 2018). O sistema, portanto, está a exigir reformas que sejam inclusivas. 
A Tabela 2 resume os dados do então Ministério da Fazenda para o total das desonerações federais para o período 2007-2017 e do valor das renúncias de receitas pertencentes à seguridade social. Em 2009, o total das desonerações foi de R\$116,1 bilhões ou 3,65\% do PIB. Em 2011, subiu para R\$ 152,4 bilhões; em 2015, para R \$282,4 bilhões; em 2017 chegou ao montante estimado em 4,19\% do PIB ou R\$284,8 bilhões. Para se ter uma ideia da magnitude dessas quantias, no ano de 2016, ela foi maior do que a soma de tudo o que foi gasto na esfera federal, naquele ano, com saúde ( $\mathrm{R}$ \$ 98,5 bilhões), educação ( $\mathrm{R} \$ 84,6$ bilhões), assistência social ( $\mathrm{R} \$ 77,6$ bilhões) e ciência e tecnologia (R\$ 5,8 bilhões) (BRASIL, 2016).

Tabela 2 - Desonerações Tributárias (em R\$ milhões correntes e em \% do PIB)

\begin{tabular}{|c|c|c|c|c|c|c|c|c|}
\hline \multirow[b]{2}{*}{ Ano } & \multirow[b]{2}{*}{$\begin{array}{c}\text { Desoneração } \\
\text { Total }\end{array}$} & \multirow[b]{2}{*}{$\%$ do PIB } & \multicolumn{4}{|c|}{ Desonerações de Contribuições Sociais } & \multirow{2}{*}{$\begin{array}{c}\text { Total das } \\
\text { Desonerações } \\
\text { de Receitas da } \\
\text { Seguridade } \\
\text { Social }\end{array}$} & \multirow[b]{2}{*}{$\begin{array}{l}\% \text { do } \\
\text { PIB }\end{array}$} \\
\hline & & & $\begin{array}{c}\text { Contrib. p/ } \\
\text { Previdência } \\
\text { Social }\end{array}$ & COFINS & CSLL & $\begin{array}{c}\text { PIS/ } \\
\text { PASEP }\end{array}$ & & \\
\hline 2007 & 102.673 & 3,95 & n.d. & 13.351 & 2.958 & 2.377 & 18.686 & 0,81 \\
\hline 2008 & 114.755 & 3,78 & n.d. & 20.058 & 4.525 & 3.732 & 28.315 & 1,03 \\
\hline 2009 & 116.098 & 3,65 & 17.905 & 29.418 & 6.087 & 5.651 & 59.061 & 1,85 \\
\hline 2010 & 113.861 & 3,60 & 18.183 & 33.883 & 8.333 & 6.955 & 67.354 & 2,02 \\
\hline 2011 & 152.406 & 3,68 & 21.156 & 34.618 & 5.830 & 6.542 & 68.146 & 1,75 \\
\hline 2012 & 182.410 & 4,15 & 24.412 & 41.376 & 6.976 & 8.145 & 80.909 & 1,78 \\
\hline 2013 & 225.630 & 4,66 & 33.743 & 46.142 & 8.788 & 9.060 & 97.733 & 1,97 \\
\hline 2014 & 253.902 & 4,92 & 57.012 & 58.510 & 9.301 & 11.639 & 136.462 & 2,60 \\
\hline 2015 & 282.437 & 4,93 & 62.519 & 70.538 & 10.490 & 14.100 & 157.647 & 2,75 \\
\hline 2016 & 271.006 & 4,33 & 54.349 & 64.558 & 11.171 & 12.887 & 142.965 & 2,29 \\
\hline 2017 & 284.846 & 4,19 & 62.493 & 64.023 & 11.792 & 12.720 & 151.028 & 2,22 \\
\hline
\end{tabular}

Nota: Dados de 2007 a 2014, Bases Efetivas. Dados de 2015 e 2017, dados estimados c/ base no PLOA-Projeções. Fonte: Elaboração própria com base nos dados da Receita Federal, Ministério da Fazenda, Demonstrativo dos Gastos Tributários, PLOA (projeções) e Relatório de Bases Efetivas.

É importante chamar a atenção para os valores das renúncias tributárias na área específica da seguridade social. Em 2009, por exemplo, a renúncia de contribuições sociais foi de R 59 bilhões, ou 1,85\% PIB. Em 2015, o valor alcançou o ponto máximo de R\$ 157,6 bilhões, quase 3\% do PIB. Isso significa que mais da metade das renúncias de receita do governo federal é feita com recursos da seguridade social que deveriam estar financiando a saúde pública, as aposentadorias e as pensões e todas as demais políticas de combate à pobreza. Nesse sentido, é possível constatar que há margem para aumento de arrecadação de receitas da Previdência pela via da revisão das renúncias de contribuições sociais. 
Destaque-se que a política de desoneração tributária não surtiu o efeito de estímulo ao investimento privado esperado pelo governo porque, entre 2011-2015, os juros mantiveram-se muito elevados e houve queda do investimento público, duas políticas de sentido contrário, que provocam contração de demanda. Sobre esse assunto, cabe resgatar a análise clássica de Kalecki (1944), que trata das estratégias para alcançar o pleno emprego. Apesar de o autor recomendar a adoção de políticas de estímulo ao investimento privado mediante a redução na taxa de juros e a diminuição de impostos, ele ressaltava que tais políticas são muito menos satisfatórias se comparadas ao dispêndio do governo em investimentos públicos ou em subsídios ao consumo popular.

Nesse sentido, é possível afirmar que a política fiscal do governo, além de contraditória dentro de seu próprio escopo (combinando redução de tributos e redução de investimento público), não seguiu a necessária complementaridade com a política monetária, que manteve juros elevados por longo período.

\section{Redução da desvinculação das receitas da seguridade social}

Por meio da Desvinculação das Receitas da União (DRU) o governo pode retirar $30 \%$ das receitas que são originalmente destinadas à seguridade social para gastar em qualquer área, inclusive para pagar juros da dívida pública. Antes de 2016, esse percentual era de 20\%. Porém, em 2016, o Congresso Nacional renovou a DRU e aumentou de $20 \%$ para $30 \%$ a alíquota que pode ser desvinculada da seguridade social, produzindo uma acentuada queda nas receitas que deveriam ser aplicadas na área social, conforme determina a Constituição Federal.

A Associação Nacional dos Auditores Fiscais da Receita Federal do Brasil (ANFIP e FUNDAÇÃO ANFIP, 2016), com base em dados da Secretaria do Tesouro Nacional, estima que o desvio anual de receitas da seguridade social com a DRU passou de R\$34 bilhões em 2005 para R $\$ 63$ bilhões no ano de 2014. Entre 2010 e 2014, foram retirados da seguridade social R $\$ 230,5$ bilhões por meio da DRU. Com o aumento do percentual de $20 \%$ para $30 \%$, estima-se que, a partir de 2017 , poderão ser desvinculados cerca de R\$ 120 bilhões de contribuições sociais ao ano.

Sendo assim, via desvinculações, o governo retira um montante extremamente significativo de recursos que seriam destinados à Previdência Social. Se esses recursos fossem de fato destinados à seguridade, conforme determina os artigos 194 e 195 da Constituição Federal de 1988, a Previdência Social não seria deficitária (GENTIL, 2007, 2019b).

\section{Recuperação de créditos da Previdência de forma mais eficiente}

A dívida ativa Previdenciária da União é o conjunto de débitos não pagos, de empresas e de pessoas físicas, para com o Instituto Nacional do Seguro Social (INSS). Assim, após o devido processo legal, os órgãos da Procuradoria Geral da Fazenda 
Nacional (PGFN) podem ingressar judicialmente contra os contribuintes devedores, em processo de execução fiscal.

O estoque da dívida previdenciária é crescente e a capacidade do governo federal de cobrar e recuperar esse crédito junto aos devedores mostra-se deficiente. No ano de 2011, o estoque da dívida ativa previdenciária era de $\mathrm{R} \$ 215,3$ bilhões e, naquele ano, o percentual recuperado foi de apenas 1,2\%. Em 2013, a dívida ativa subiu para R 255 bilhões e, novamente, só 1,2\% foram resgatados. Em 2017 alcançou R \$ 430,4 bilhões e meramente $1,3 \%$ foi retomado (Tabela 3 ).

Tabela 3 - Dívida Ativa Previdenciária, Brasil, 2011-2017 (em R\$ bilhões nominais)

\begin{tabular}{lcccc}
\hline Ano & $\mathbf{2 0 1 1}$ & $\mathbf{2 0 1 3}$ & $\mathbf{2 0 1 5}$ & $\mathbf{2 0 1 7}$ \\
\hline Estoque da dívida (a) & 215,3 & 255,1 & 358,7 & 430,4 \\
Arrecadação (b) & 2,7 & 3,0 & 3,7 & 5,7 \\
Percentual recuperado (b/a) & 1,2 & 1,2 & 1,0 & 1,3 \\
\hline
\end{tabular}

Fonte: Elaboração própria com base nos dados da Procuradoria Geral da Fazenda Nacional (BRASIL, 2018).

Diante da crescente sonegação de recursos da previdência social, constata-se que a gestão mais eficiente da dívida ativa resultaria em reconquista de fontes significativas de receitas para o financiamento da Previdência Social.

\section{Redução do saldo conta única do Tesouro Nacional no Banco Central}

A Conta Única do Tesouro Nacional contempla as disponibilidades do governo federal que ficam depositadas no Banco Central. Os recursos ali depositados representam o acúmulo de superavit primários de exercícios anteriores (conquistados com recursos de receitas de contribuições sociais que são vinculadas à seguridade social) e receitas de operações financeiras de venda de títulos públicos. Conforme definem Pimentel e Serrano:

O Tesouro Nacional se refere à parte do saldo da conta única como um colchão de liquidez preparado para os possíveis resgates dos títulos públicos que estão vencendo por parte do setor privado. Entretanto, em geral, a dívida pública é refinanciada (e não paga ou liquidada) de modo que os recursos da conta única são utilizados para os pagamentos do governo federal em geral. (PIMENTEL e SERRANO, 2016, p. 3)

A Figura 3, a seguir, demonstra que, em 11 anos, as disponibilidades do governo federal no Banco Central do Brasil (medidas a preços de 2017) passaram de R\$394,3 bilhões em 2006 para R\$ 1,07 trilhão em 2017. Com essas significativas quantias retidas na Conta 
Única, o governo torna crível, ao mercado financeiro, as altas taxas de juros que remuneram os títulos públicos, assegurando aos seus proprietários liquidez e certeza de retorno.

As elevadas disponibilidades do governo federal na conta única se transformaram em recursos que ficam empoçados no Banco Central, sem ingressar no circuito produtivo, impedidos de se transformar em bens e serviços que atendam às necessidades da população, em transferências de renda na forma de benefícios previdenciários e em investimentos públicos que permitam gerar emprego, renda e novas tecnologias. O uso efetivo desses recursos, hoje esterilizados no Banco Central, geraria menor pressão sobre o resultado primário, liberando a política fiscal para estratégias mais inclusivas e redistributivas.

Figura 3 - Disponibilidade do Governo Federal no Banco Central, Conta Única, saldo em dezembro, 2006-2017 (a preços de 2017)

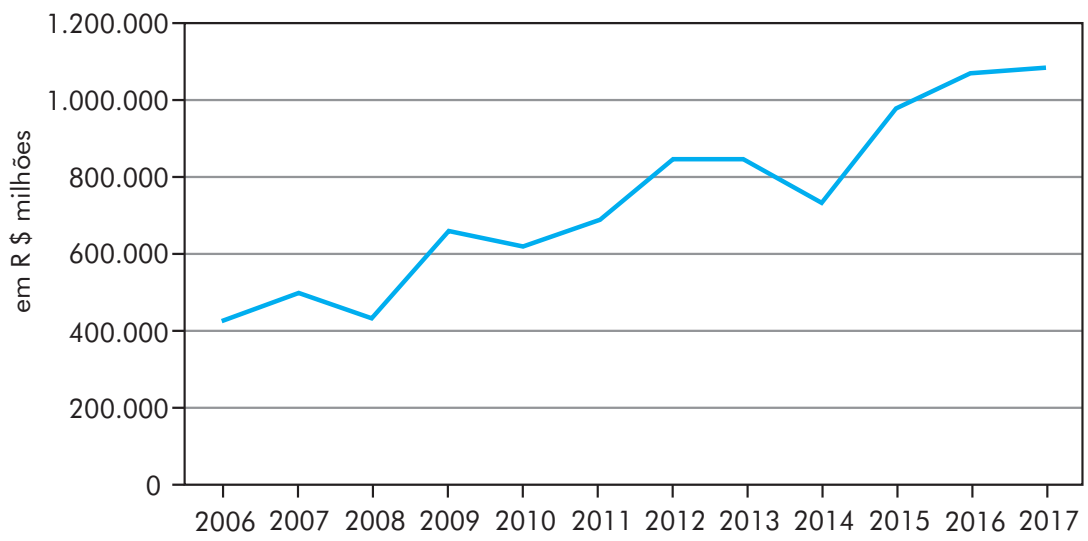

Fonte: Elaboração própria com base em dados do Banco Central do Brasil (BCB, vários anos).

Como se pode demonstrar nesta seção do artigo, o Brasil possui um rico repertório de alternativas de ampliação de receitas da seguridade social para o qual se poderia recorrer nos momentos de recessão econômica e de elevação da trajetória de gastos, que podem dar viabilidade de longo prazo para o sistema previdenciário. A próxima seção simulará o impacto do uso de alguns desses recursos no resultado fiscal da previdência social.

\section{SIMULAÇÃO DOS EFEITOS DE ELEVAÇÕES NA PRODUTIVIDADE, EMPREGO E EFICIÊNCIA DE RECEITAS SOBRE OS RESULTADOS DA PREVIDÊNCIA SOCIAL}

Feitas as discussões teóricas sobre as variáveis que influenciam o resultado da previdência social, bem como a exposição da trajetória dessas variáveis no Brasil, esta seção faz uma 
tentativa de simular como seriam os resultados da previdência uma vez que sejam consideradas variáveis que contribuam para afetar o lado da receita, sem a ênfase constante às variáveis que afetam as despesas, como o faz a visão tradicional. Todas as simulações foram executadas utilizando o software descrito em Da Silva (2017).

Uma possível dificuldade dessa parte da pesquisa é que nem todas as variáveis discutidas nas seções anteriores estão incluídas no modelo oficial utilizado para projetar os resultados da previdência social no Brasil. Outro obstáculo é o baixo grau de transparência dos métodos utilizados pelo governo federal na projeção dos resultados previdenciários do RGPS.

Feitas essas considerações, o exercício de simulação que será apresentado nesta seção compara um cenário base, mais precisamente o cenário oficial do governo federal aproximado, com três diferentes possibilidades que serão testadas: cenário pessimista; cenário moderado; e cenário otimista. Nesses três cenários serão considerados choques positivos em variáveis como receita da previdência social, produtividade do trabalho e emprego formal.

No caso da receita da seguridade social, como sugerido na seção anterior deste artigo, seu aumento poderia advir de: revisão das desonerações tributárias; redução das desvinculações dos recursos da seguridade social; recuperação, de forma mais eficiente, dos créditos da Previdência inscritos em dívida ativa; e, até mesmo, o uso parcial dos recursos que compõem o colchão de liquidez para resgate de títulos públicos e que corresponderiam a uma parcela do saldo da conta única do Tesouro Nacional no Banco Central.

No que tange a produtividade, foi mencionado que seu aumento contribui para que um mesmo número de trabalhadores possa ser capaz de financiar um número mais elevado de pessoas aposentadas, o que tende a reduzir a taxa de dependência da população aposentada em relação ao número de trabalhadores. No experimento aqui realizado, esse evento recebeu o tratamento equivalente a um aumento no número efetivo de trabalhadores na economia.

Por fim, no que se refere ao aumento do emprego formal, foi apontado que este pode ser estimulado, por exemplo, pelo crescimento econômico sustentável no longo prazo, sendo ambos variáveis-chave para o financiamento da previdência social, por levarem ao aumento no número de contribuintes e na receita da previdência social.

Sendo assim, a tabela 4 indica alguns números que serão utilizados como referência para as projeções das respectivas variáveis, nos três cenários elaborados.

No que concerne aos modelos matemáticos utilizados para as projeções da receita e despesa da previdência social, eles são os mesmos descritos no Anexo IV (Metas Fiscais) da Lei de Diretrizes Orçamentárias (LDO) de 2013 (BRASIL, 2014). 
Tabela 4 - Cenários sugeridos de crescimento de receita, produtividade e emprego

\begin{tabular}{lccc}
\hline Cenários & Produtividade & Receita & Emprego Formal \\
\hline Cenário pessimista & $0,7 \%$ & $1,3 \%$ & $1,5 \%$ \\
Cenário moderado & $1,0 \%$ & $2,0 \%$ & $2,0 \%$ \\
Cenário otimista & $1,2 \%$ & $3,5 \%$ & $2,4 \%$ \\
\hline
\end{tabular}

Fonte: Elaboração própria.

Para o cálculo das despesas, inicialmente, devem-se calcular os estoques de benefícios. Todas as variáveis nas equações têm quatro ou cinco índices. Os parâmetros de indexação seguem as definições e os conjuntos de valores descritos no Quadro 1.

\begin{tabular}{lcc} 
& \multicolumn{2}{c}{ Quadro 1 - Parâmetros de indexação e notação geral } \\
\hline Variável & Significado & Valores \\
\hline$i$ & Idade & $0,1, \ldots, 80$ \\
$t$ & Ano & $2012,2013, \ldots, 2060$ \\
$s$ & Sexo & homem ou mulher \\
$c$ & Clientela & urbana ou rural \\
$k$ & Tipo de benefício & aposentadorias, auxílios, pensões, etc. \\
\hline
\end{tabular}

Fonte: Elaboração própria.

Os valores dos quantitativos de benefícios foram calculados pelo método dos fluxos, segundo o qual primeiro se determinam os fluxos para posteriormente se chegar aos valores dos estoques. Os fluxos de concessão de benefícios são calculados como sendo:

$$
F B(i, t, s, c, k)=P(i, t, s, c) * P B(i, t, s, c, k)
$$

Em (8) FB é o fluxo de entrada nos benefícios do tipo $k$ com idade $i$, no ano $t$ para o sexo $s$ e clientela $c$; $P$ é a população e $P B$ é a probabilidade de entrada no benefício. Por sua vez, o estoque de benefícios é dado pela equação (2):

$$
E B(i, t, s, c, k)=E B(i-1, t-1, s, c, k)^{*} P S(i, t, s, c)+F B(i, t, s, c, k)
$$

Em (9), EB representa o estoque de benefícios do tipo $k$; $P S(i, t, s, c)$ é a probabilidade de um indivíduo do sexo $s$ e clientela $c$ sobreviver da idade $i-1$ no ano $t-1$ a idade $i$ no ano $t$.

Como corolário, obtém-se que o estoque total de benefícios no ano $t$ é dado por:

$$
\sum i \sum s \sum c \sum k E B(i, t, s, c, k)
$$


A despesa com benefícios é determinada a partir do conhecimento do estoque de benefícios e de seu valor médio, tal como pode ser observado nas equações abaixo.

$$
\begin{aligned}
& D E B(i, t, s, c, k)=E B(i-1, t-1, s, c, k) * P S(i, t, s, c) * V E B(i, t, s, c, k)+ \\
& F B(i, t, s, c, k)^{*} \operatorname{VFB}(i, t, s, c, k)
\end{aligned}
$$

Em (11), $D E B$ é a despesa com estoque de benefícios, $V E B$ é o valor médio anual do benefício pago ao estoque de benefícios e $V F B$ é o valor médio anual do benefício pago ao fluxo de entrada dos benefícios.

A quantidade de contribuintes no ano $t$ é determinada por:

$$
\begin{aligned}
& \sum i \sum s \sum c C(i, t, s, c)=\sum i \sum s \sum c P(i, t, s, c) * \operatorname{Part}(i, t, s, c) * \\
& {[1-\operatorname{Desemp}(i, t, s, c)]^{*} d(i, t, s, c)}
\end{aligned}
$$

Em (12), $i$ é a idade; $s$ o sexo; $c$ a clientela; $C$ é o estoque de contribuintes; Part é a taxa de participação; Desempé a taxa de desemprego e $d$ é a densidade de contribuição. ${ }^{14}$ Após o cálculo da quantidade de contribuintes, tem-se que o valor da receita $R$ no ano $t$ é dado por:

$$
R t=\sum i \sum s \sum c C(i, t, s, c) *[\tau 1 * \operatorname{Min}(T, W(i, t, s, c))+\tau 2 * W(i, t, s, c)]
$$

Em (13), $\tau 1$ é a alíquota de contribuição previdenciária sobre o empregado, $\tau 2$ é a alíquota de contribuição previdenciária sobre o empregador, Té o teto de contribuição e $W$ é o salário.

Nas projeções de receita, apenas as contribuições previdenciárias advindas dos empregados e empregadores sobre a folha de pagamentos foram consideradas. ${ }^{15}$ Além disso, a remuneração dos trabalhadores foi reajustada ao longo dos anos projetados pelo Índice Nacional de Preços ao Consumidor (INPC). Nas projeções de despesa, foram considerados os seguintes benefícios: aposentadorias (por idade, invalidez e tempo de contribuição), auxílio doença e pensões. Os principais dados e parâmetros utilizados para as projeções são descritos no Quadro 2.

\footnotetext{
${ }^{14}$ A densidade de contribuição representa a proporção de meses que um empregado contribui anualmente, ou seja, $d=1$ significa que um empregado contribuiu todos os meses em um ano.

15 A receita da previdência possui diversas fontes (vide Tabela 41.4 do Anuário Estatístico da Previdência Social de 2013), porém o modelo descrito no Anexo IV da LDO considera somente as contribuições dos trabalhadores e empresas.
} 
Quadro 2 - Parâmetros utilizados nas projeções, Brasil, 2015/2050

\begin{tabular}{ll}
\hline Período Projetado & 2015/2050 \\
\hline Dados populacionais & $\begin{array}{l}\text { Retirado do Anexo IV Metas Fiscais da LDO - Lei de Diretrizes Orçamentárias } \\
\text { de 2013 (BRASIL, 2012) }\end{array}$ \\
Taxas de Urbanização & $\begin{array}{l}\text { Retirado do Anexo IV Metas Fiscais da LDO - - Lei de Diretrizes Orçamentárias } \\
\text { de 2013 (BRASIL, 2012) }\end{array}$ \\
$\begin{array}{l}\text { Taxas de Participação na Força de } \\
\text { Trabalho }\end{array}$ & PNAD 2009 (IBGE, 2009) \\
Taxas de Desemprego & Dados da DATAPREV de 2014 (DATAPREV, 2014) \\
Estoque de benefícios & Dados da DATAPREV de 2014 (DATAPREV, 2014) \\
Despesas com benefícios & Dados da DATAPREV 2014 (DATAPREV, 2014) \\
Remuneração Média dos & Anexo IV Metas Fiscais da LDO - Lei de Diretrizes Orçamentárias de 2013 \\
Trabalhadores & (Tabela 5.1) (BRASIL, 2012) \\
Reajuste do Salário Mínimo & $\begin{array}{l}\text { Anexo IV Metas Fiscais da LDO - - Lei de Diretrizes Orçamentárias de 2013 } \\
\text { (Tabela 5.1) (BRASIL, 2012) }\end{array}$ \\
Reajuste dos Benefícios & $\begin{array}{l}\text { Anexo IV Metas Fiscais da LDO - Lei de Diretrizes Orçamentárias de 2013 } \\
\text { (Tabela 5.1) (BRASIL, 2012) }\end{array}$ \\
\hline
\end{tabular}

Nota: As taxas constantes na LDO de 2013 são baseadas na PNAD de 2005.

Fonte: Elaboração própria.

Além da avaliação dos cenários descritos na Tabela 4, para uma melhor visualização dos efeitos da produtividade, formalização do trabalho e eficiência da receita, foi definido um cenário de referência. O cenário de referência projeta a receita e despesa utilizando exatamente as equações do governo, descritas na LDO, ou seja, sem ganhos de produtividade, aumento do emprego formal ou melhoria na eficiência da receita. ${ }^{16}$

Antes de se proceder às avaliações dos resultados financeiros do RGPS, é interessante avaliar o comportamento da relação de dependência no Brasil, quando considerada a elevação da produtividade do trabalho e o aumento do emprego formal. Conforme descrito na seção 3.1, a possibilidade de crescimento da produtividade e do emprego formal dá origem à razão de dependência econômica efetiva, na qual o número de trabalhadores efetivos é maior que o número de trabalhadores reais. A Figura 4 ilustra a razão de dependência para os quatro cenários (de referência, pessimista, moderado e otimista).

${ }^{16}$ Para as dificuldades de se reproduzir os cálculos do resultado oficial da previdência social no Brasil, ver Puty e Gentil (2017). 
Analisando o cenário de referência (do governo), temos que o sistema tende a uma situação caótica, na qual a relação de dependência se aproxima de 0,73 (1 aposentado para 1,3 trabalhadores). Porém, quando se considera a possibilidade de incremento da produtividade do trabalho e da formalização, observa-se uma melhora considerável nos resultados. Para o cenário pessimista, temos uma relação de dependência que passa de 0,47 (1 aposentado para 2,12 trabalhadores). E para os demais cenários, a produtividade e a formalização levam a relação de dependência a valores próximos de 0,35 (1 aposentado para 2,85 trabalhadores) no caso do cenário otimista, e 0,40 (1 aposentado para 2,5 trabalhadores) no caso do cenário moderado. ${ }^{17}$

\section{Figura 4 - Evolução da taxa de dependência efetiva no Brasil, 2015-2050}

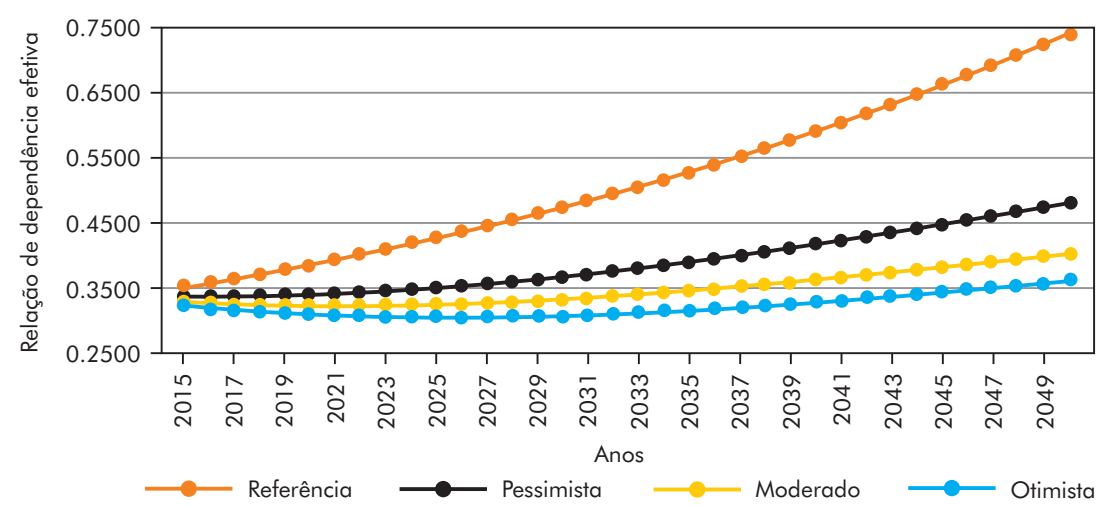

Fonte: Elaboração própria com base nos resultados da simulação.

17 Segundo Palley (1998), que realiza esse mesmo cálculo para os Estados Unidos, o crescimento da produtividade de 1950 a 1970 foi em média de 3\% ao ano, de 1970 a 1980 em torno de $2 \%$ ao ano e, desde então, vem crescendo cerca de $1 \%$ ao ano. O autor utiliza essas taxas de crescimento da produtividade para calcular o número de trabalhadores efetivos e a taxa efetiva de dependência para os Estados Unidos. Ao comparar esta última à razão de dependência que não considera os incrementos da produtividade, ela cai continuamente, desaparecendo a indicação de uma crise iminente resultante do envelhecimento da população. A razão de dependência, em 1980, nos Estados Unidos era de 1,14, já a razão de dependência efetiva foi de 0,51. Em 1995, esta última caiu para 0,40 dependentes por trabalhador efetivo, e em 2040 está previsto que seja de apenas 0,29 dependentes por trabalhador efetivo, baseando-se em um crescimento da produtividade do trabalho de 1\% ao ano no período 1995-2040. Diante dessa análise, o autor destaca que a relação de dependência econômica efetiva fornece a verdadeira medida para a sociedade do peso da população não economicamente ativa. Para a sociedade como um todo, no caso dos Estados Unidos, esse peso tem se reduzido. No entanto, esclarece Palley (1998), isso não significa que, para os trabalhadores, o referido peso tenha se reduzido, pois isso só ocorre quando os trabalhadores também colhem os frutos do progresso técnico, recebendo salários mais altos. Se os salários não aumentarem, então, o encargo para os trabalhadores do maior número de aposentados aumentará. 
As Figuras 5, 6, 7 e 8 mostram o resultado financeiro do RGPS, considerando os diferentes cenários sugeridos na Tabela 4, além do cenário de referência. Neste último (ilustrado na Figura 5), que contém os dados de projeções do governo federal para o RGPS, o deficit da previdência alcança o valor de R\$ 618 bilhões em 2035, R\$ 825 bilhões em 2040 e R \$ 1,447 trilhão em 2050. É, portanto, uma previsão de futuro com deficit explosivos que tem sido usada como justificativa para a proposta de uma severa reforma da previdência.

Figura 5 - Cenário de referência (governo), resultado financeiro do RGPS, Brasil, 2015-2050 (em R\$ bilhões)

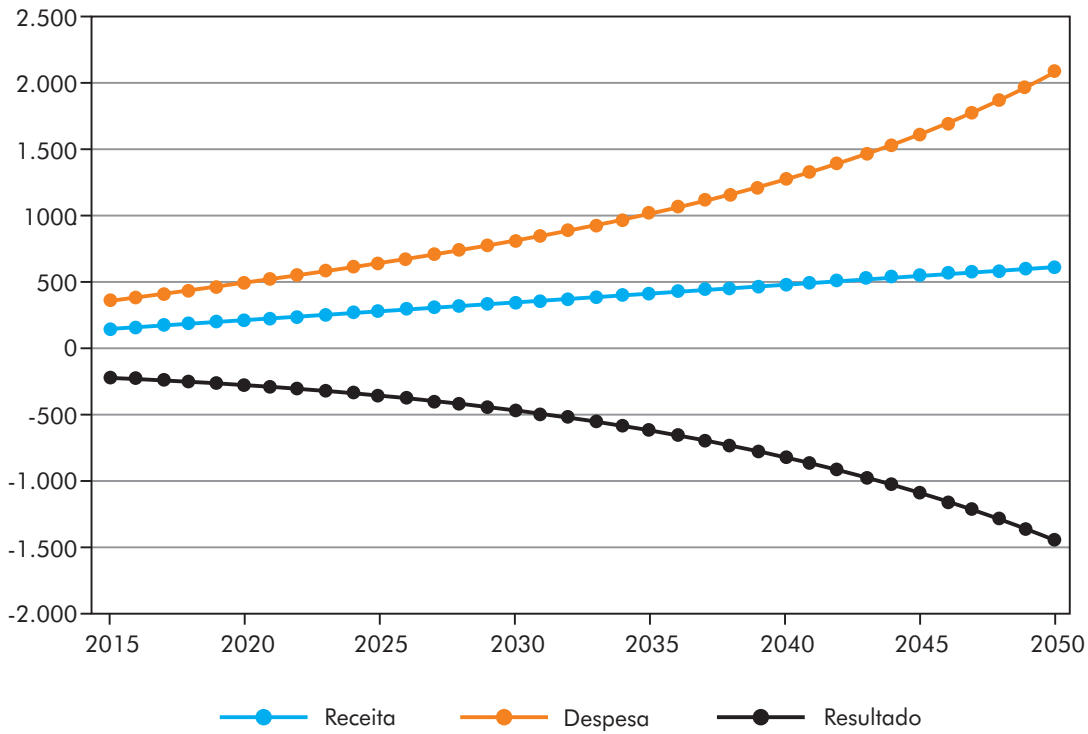

Fonte: Elaboração própria com base nos resultados da simulação.

Na Figura 6, a seguir, é demonstrado o cenário pessimista testado neste artigo. Nele a produtividade cresceria à taxa anual de $0,7 \%$; a maior eficiência na gestão da receita da previdência faria com que está se elevasse à taxa média anual de 1,3\% e o emprego formal aumentaria à taxa de 1,5\% ao ano. A relação de dependência seria de 0,7 em 2050, ou seja, haveria 1,2 ativos para cada inativo. Os valores dessas variáveis não permitiriam a existência de equilíbrio atuarial no longo prazo. Em 2050, o deficit alcançaria o patamar de $\mathrm{R} \$ 660$ bilhões, significativamente inferior àquele previsto pelo cenário de referência do governo federal. 
Figura 6 - Cenário pessimista, resultado financeiro do RGPS, Brasil, 2015-2050 (em R\$ bilhões)

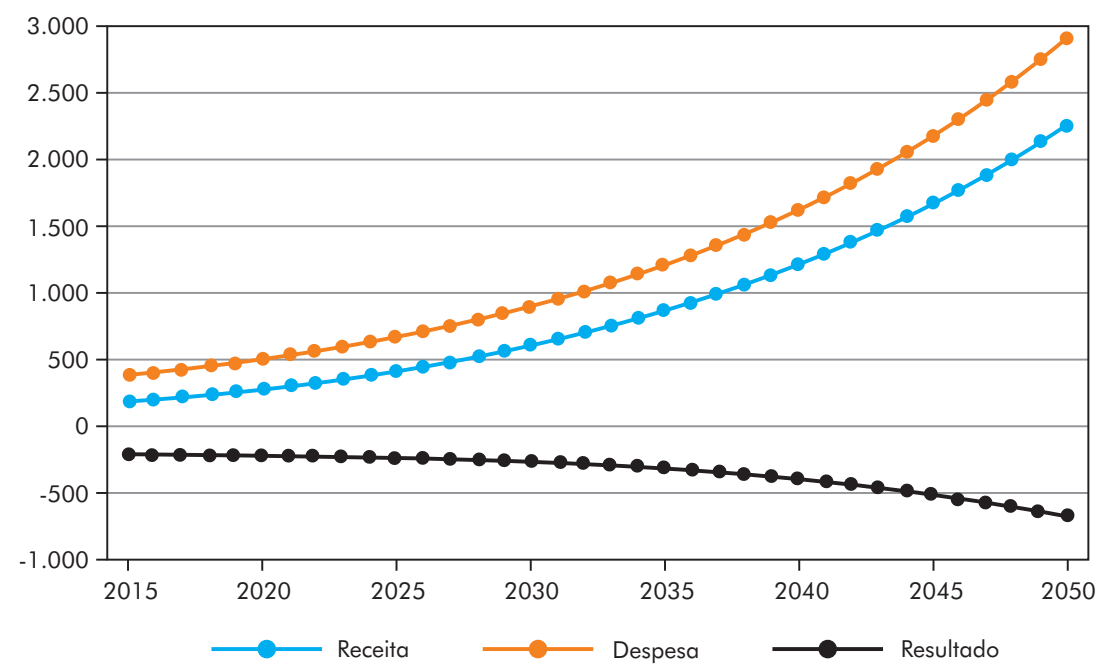

Fonte: Elaboração própria com base nos resultados da simulação.

Na Figura 7, é apresentado um cenário moderado. Nele a produtividade cresceria anualmente à taxa de $1,5 \%$; a maior eficiência na gestão da receita da previdência faria com que essa se elevasse à taxa média anual de 2,0\% e o emprego formal aumentaria à taxa de 2,0\% ao ano. A relação de dependência seria de 0,40 em 2050, ou seja, haveria 2,5 ativos para cada inativo. Os valores dessas variáveis permitiriam a existência de superavit atuarial no longo prazo a partir de 2038. Portanto, no longo prazo, num cenário moderado, considerando o comportamento das despesas como se fosse igual ao do cenário de referência (do governo) e estimulando o crescimento das receitas pelas vias demonstradas neste artigo (com ganhos de produtividade, aumento do emprego formal e melhoria na eficiência da gestão de receita), o resultado atuarial da previdência seria superavitário. Isso ocorreria ainda que as demais receitas de contribuições sociais (Cofins, CSLL, PIS/PASEP, receita de concursos de prognósticos) não fossem consideradas, como se faz aqui, neste exercício (ver Figura 6).

Na Figura 8, é ilustrado o cenário otimista. Nele a produtividade cresceria anualmente à taxa de 1,2\%; a maior eficiência na gestão da receita da previdência faria com que está se elevasse à taxa média anual de 3,5\% e o emprego formal aumentaria à taxa de 2,4\% ao ano. A relação de dependência seria de 0,32 em 2050, ou seja, haveria 2,8 ativos para cada inativo. Os valores dessas variáveis permitiriam a existência de superavit atuarial no longo prazo a partir de 2027. 
Figura 7 - Cenário moderado, resultado financeiro do RGPS, Brasil, 2015-2050 (em R\$ bilhões)

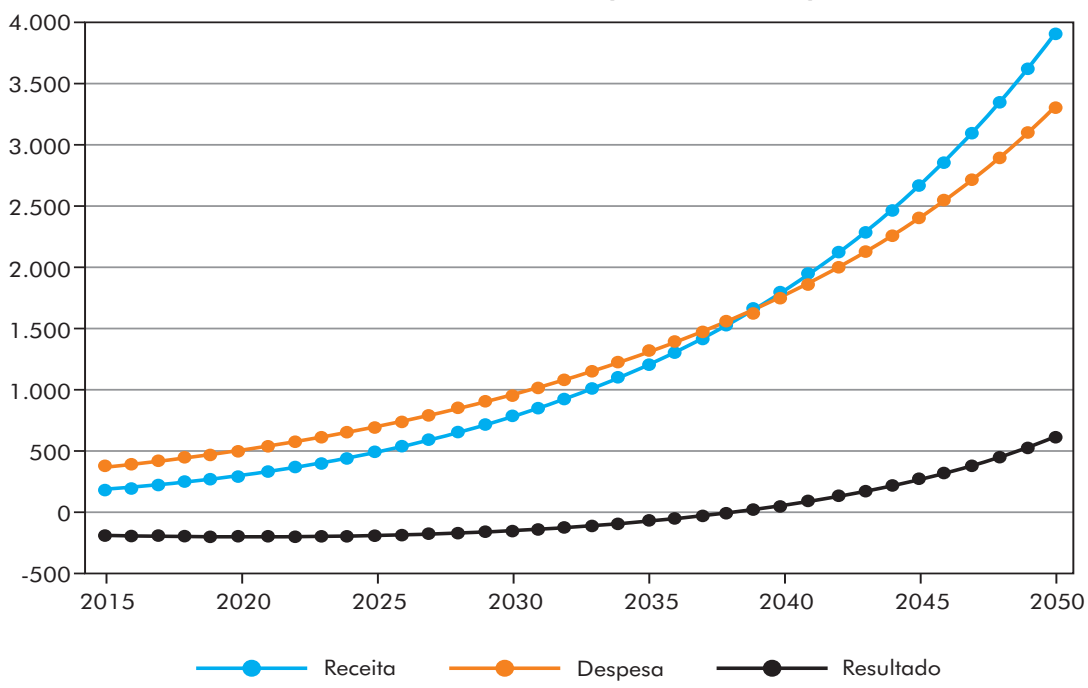

Fonte: Elaboração própria com base nos resultados da simulação.

Figura 8 - Cenário otimista, resultado financeiro do RGPS, Brasil, 2015-2050 (em R\$ bilhões)

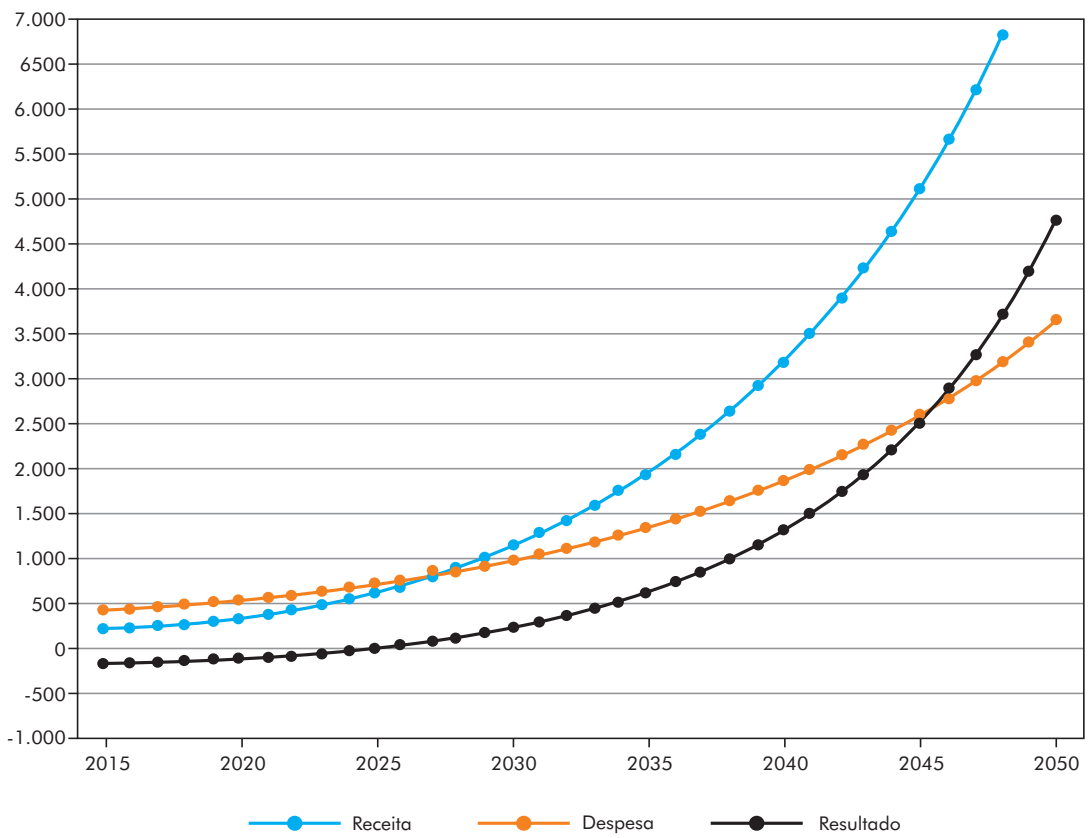

Fonte: Elaboração própria com base nos resultados da simulação. 
Assim, no longo prazo, num cenário otimista, considerando o comportamento das despesas como se fosse o mesmo do cenário de referência (do governo) e estimulando o crescimento das receitas pelas vias demonstradas neste artigo (com ganhos de produtividade, aumento do emprego formal ou melhoria na eficiência da arrecadação de receitas), o resultado atuarial da previdência seria superavitário. Isso ocorreria independentemente da contabilização das demais receitas de contribuições sociais (Cofins, CSLL, PIS/PASEP, receita de concursos de prognósticos), como se faz aqui, neste estudo (ver Figura 8).

\section{CONSIDERAÇÕES FINAIS}

Neste artigo o objetivo foi investigar outras variáveis que poderiam contribuir para a geração de resultados positivos para o financiamento da previdência social brasileira, diferindo das soluções sugeridas pelas propostas de reforma da previdência social encampadas pelos governos Michel Temer (2016-2018) e Jair Bolsonaro (2019-2022), cujo foco é a redução dos valores dos benefícios assistenciais e previdenciários.

Com esse intuito, foi apresentado um modelo teórico baseado em Eatwell (2002), o qual sugere que a crise da previdência social pode ser contornada por três diferentes políticas: incrementos na produtividade do trabalho; aumento da poupança e dos impostos (receitas da previdência); e aumento na taxa de crescimento do emprego formal, isto é, do número de contribuintes.

A possibilidade de melhoria no comportamento dessas variáveis importantes para os resultados financeiros da previdência social foi considerada em um exercício de simulação, que aplicou choques positivos na produtividade do trabalho, nas receitas da previdência e no número de trabalhadores formais. O resultado desse exercício muda significativamente a versão de que o envelhecimento da população levará a uma crise do sistema de previdência social brasileiro. Isso porque o crescimento da produtividade e da formalização do trabalho - número de contribuintes - resulta em uma redução da taxa de dependência efetiva, isto é, com trabalhadores mais produtivos a quantidade de produto que se obtêm utilizando uma unidade de trabalho é maior, de forma que o número de trabalhadores é aumentado pelo efeito cumulativo do crescimento da produtividade.

Associando os choques nessas duas variáveis - produtividade e número de trabalhadores formais - aos choques positivos na gestão das receitas da previdência, constata-se que o resultado financeiro do RGPS (receitas menos despesas totais) tona-se positivo no curto e longo prazo.

A implicação desse resultado é a de que, ao invés de enfatizar cortes nos valores dos benefícios previdenciários e assistências, medidas que levem ao aumento das 
receitas da previdência são fundamentais. A política macroeconômica expansiva, associada à política industrial de recuperação do parque industrial e à maior eficiência na gestão das receitas previdenciárias são estratégias essenciais para obter o equilíbrio atuarial da previdência social no Brasil. Num momento de profunda recessão, em que a redução das transferências de renda às famílias só acarretaria em menor crescimento e maior empobrecimento da população já penalizada pela crise, a ênfase na análise de variáveis até hoje desconsideradas pelo mainstream torna-se o caminho para jogar mais luz sobre o debate dos rumos da previdência no Brasil.

\section{REFERÊNCIAS}

ANFIP - ASSOCIAÇÃO NACIONAL DOS AUDITORES-FISCAIS DA RECEITA FEDERAL DO BRASIL; FUNDAÇÃO ANFIP DE ESTUDOS TRIBUÁRIOS. Análise da Seguridade Social. Brasília: Anfip, 2016.

BARR, N. The economics of the welfare states. 4. ed. London: Oxford University Press, 2004.

BARR, N.; DIAMOND, P. Reforming pensions: principles and policy choices. New York and Oxford: Oxford University Press, 2008.

BCB - BANCO CENTRAL DO BRASIL. Taxa de juros básicas - Histórico. [On-line] BCB, vários anos. Disponível em: <https://www.bcb.gov.br/controleinflacao/historicotaxasjuros> Acesso em: 5 mar. 2020.

BLS - BUREAU OF LABOR STATISTICS. Employment projections. [On-line] BLS, 2019. Disponível em: <https://www.bls.gov/emp/tables/economic-dependency-ratio.htm.

BRASIL. Envelhecimento da População e Seguridade Social. Coleção Previdência Social, Série Estudos, v. 37. Brasília: Ministério da Fazenda, Secretaria de Previdência, 2018.

BRASIL. Despesas da União. Séries Históricas. Vários Anos. [On-line] Tesouro Nacional, 2019. Disponível em: <https://www.tesourotransparente.gov.br/publicacoes/despesas-da-uniaoseries-historicas/2019/11>. Acesso em: 30 ago. 2020.

BRASIL. PGFN em Números, 2017. Brasília: Procuradoria Geral da Fazenda Nacional, 2018. Disponível em: <https://www.gov.br/pgfn/pt-br/acesso-a-informacao/institucional/pgfnem-numeros-2014/pgfn_em_numeros_final_2_web.pdf.> Acesso em: 30 ago. 2020.

BRASIL. Lei Complementar no 101, de 4 de maio de 2000. Anexo IV (Metas Fiscais). IV.5 - Projeções Atuariais para o Regime Geral de Previdência Social (RGPS). Brasília: Ministério da Previdência Social, Secretaria de Políticas de Previdência Social, mar. 2014. Disponível em: https://www12.senado.leg.br/orcamento/documentos/ldo/2015/elaboracao/projeto-de-lei/ proposta-do-poder-executivo/anexo-iv.5-2013-projecoes-atuariais-para-o-regime-geral-deprevidencia-social-2013-rgps/view.

BRASIL. LDO - Lei de Diretrizes Orçamentária de 2013. Brasília: Câmara dos Deputados, 2012. Disponível em: https://www2.camara.leg.br/orcamento-da-uniao/leis-orcamentarias/ldo/2013/ tramitacao/redacao-final/copy2_of_redacao-final.html. Acesso em: 5 mar. 2020. 
DA SILVA, C. P. Uma metodologia para aferição da acurácia de modelos de projeção de longo prazo para a previdência social no Brasil. Tese (Doutorado em Engenharia Elétrica) Programa de Pós-Graduação em Engenharia Elétrica, Instituto de Tecnologia, Universidade Federal do Pará, Belém, Pará, Brasil, 2017.

DATAPREV, 2014. Disponível em: <https://portal2.dataprev.gov.br/>

EATWELL, J. A anatomia da "crise" da Previdência. Econômica, v. 4, n. 2, p. 177-191, 2002.

GENTIL, D. L. Política econômica e seguridade social no período pós-1994. Carta Social e do Trabalho, Cesit/Unicamp, n. 7, 2007. Disponível em: <https://cesit.net.br/wp/wp-content/ uploads/2014/11/Carta-Social-e-do-Trabalho-7.pdf $>$

GENTIL, D. L. (Coord.) Uma contribuição à avaliação das inconsistências do modelo de projeção atuarial do governo federal e dos impactos de exclusão social da PEC 06/2019. Nota Técnica $\mathrm{n}^{\circ}$ 1. Brasília: Associação Nacional dos Auditores Fiscais da Receita Federal do Brasil, Fundação ANFIP de Estudos Tributários da Seguridade Social, 2019a.

GENTIL, D. L. A política fiscal e a falsa crise da seguridade social: uma história de desconstrução e de saques. Rio de Janeiro: Mauad X, 2019b.

GGDC - GRONINGEN GROWTH AND DEVELOPMENT CENTRE. Productivity Level Database. [On-line] University of Groningen, 2020. Disponível em: <https://www.rug.nl/ ggdc/productivity/pld/>. Acesso em: 30 ago. 2020.

IBGE - INSTITUTO BRASILEIRO DE GEOGRAFIA E ESTATÍSTICA. Sistema de Contas Nacionais. Rio de Janeiro: IBGE, 2016. Disponível em: <https://www.ibge.gov.br/estatisticas/ economicas/contas-nacionais/9300-contas-nacionais-trimestrais.html? $\mathrm{t}=$ destaques $>$. Acesso em: 27 set. 2016.

IBGE - INSTITUTO BRASILEIRO DE GEOGRAFIA E ESTATÍSTICA. Pesquisa Mensal de Emprego. Rio de Janeiro: IBGE, 2015. Disponível em: <https://www.ibge.gov.br/estatisticas/ sociais/trabalho/9180-pesquisa-mensal-de-emprego.html? $=\& \mathrm{t}=0$-que-e $>$. Acesso em 5 mar. de 2020.

IBGE - INSTITUTO BRASILEIRO DE GEOGRAFIA E ESTATÍSTICA. Pesquisa Nacional por Amostra de Domicílios (PNAD). Rio de Janeiro: IBGE, 2015. Disponível em: <https://www. ibge.gov.br/estatisticas/sociais/educacao/9127-pesquisa-nacional-por-amostra-dedomicilios.html?=\&t=o-que-e $>$. Acesso em: 5 mar. 2020.

IBGE - INSTITUTO BRASILEIRO DE GEOGRAFIA E ESTATÍSTICA. Pesquisa Nacional por Amostra de Domicílios (PNAD). Rio de Janeiro: IBGE, 2009. Disponível em: <https://www. ibge.gov.br/estatisticas/sociais/educacao/9127-pesquisa-nacional-por-amostra-dedomicilios.html?=\&t=o-que-e. Acesso em: 5 mar. 2020.

IBGE - INSTITUTO BRASILEIRO DE GEOGRAFIA E ESTATÍSTICA. Projeções da População por sexo e idade - Brasil: 2000-2060 e Unidades da Federação - 2000-2030. Disponível em: <https://www.ibge.gov.br/estatisticas/sociais/populacao/9109-projecao-da-populacao. html? edicao $=9116 \& \mathrm{t}=$ resultados $>$. Acesso em: 5 mar. 2020.

IMF - INTERNATIONAL MONETARY FUND. World Economic Outlook Database. [On-line] IMF, 2016. Disponível em: <http://www.imf.org/external/pubs/ft/weo/2016/02/weodata/ index.aspx $>$. Acesso em: 12 out. 2016. 
IPEA - INSTITUTO DE PESQUISA ECONÔMICA APLICADA. Boletim Mercado de Trabalho, Conjuntura e Análise, ano 20, n. 56, fev. 2014.

KALDOR, N. Causes of the slow rate of economic growth in the United Kingdom. In: KALDOR, N. Further essays on economic theory. New York: Holmes \& Meier, 1978[1966].

KALDOR, N. Productivity and growth in manufacturing industry: a reply. In: KALDOR, N. Further Essays on Economic Theory. New York: Holmes \& Meier, 1978[1968].

KALECKI, M. Three ways to full employment. In: OSIATYNSKY, J. (Ed.) Collected works of Michal Kalecki. Oxford: Oxford University Press, 1944[1990]. v. 1.

KRUGMAN, P. The age of diminished expectations. Cambridge, MA.: The MIT Press, 1994.

LUCAS Jr., R. E. On the mechanics of economic development. Journal of Monetary Economics, n. 22 , p. 3-42, 1988.

NERI, M. A nova classe média: o lado brilhante dos pobres. São Paulo: FGV/CPS, 2010.

OREIRO, J. L. da C. Macroeconomia do desenvolvimento: uma perspectiva keynesiana. Rio de Janeiro: LTC, 2016.

PALLEY, T. I. The economics of social security: an old Keynesian perspective. Journal of Post Keynesian Economics, v. 21, n. 1, Fall 1998.

PIMENTEL, K.; SERRANO, F. Financiamento do gasto público e taxas de juros em países de moeda soberana: aspectos teóricos e o caso do Brasil. Rio de Janeiro: Instituto de Economia da UFRJ, 2016. Mimeo.

PUTY, C. A. C. B.; GENTIL, D. L. (Orgs.) A Previdência Social em 2060: as inconsistências do modelo de projeção atuarial do governo brasileiro. Brasília: ANFIP/DIEESE, Plataforma Política Social, 2017.

RADA, C. Introducing demographic changes in a model of economic growth and income distribution. Working Paper Series, Department of Economics, University of Utah from University of Utah, Department of Economics, 2009.

ROMER, P. Increasing returns and long-run growth. Journal of Political Economy, v. 94, n. 5, p. 1002-1037, Oct. 1986.

SIMÃO, A. R. A. Sistema de vigilância e fiscalização do trabalho no Brasil: efeitos sobre a expansão do emprego formal no período 1999-2007. Boletim Mercado de Trabalho Conjuntura e Análise, IPEA, n. 39, mai. 2009.

UN - UNITED NATIONS. Population dynamics. World Population Prospects. [On-line] UN, Department of Economic and Social Affairs, 2020. Disponível em: <https://population. un.org/wpp/DataQuery/>. Acesso em: 30 ago. 2020. 